\title{
Prevalence and Antifungal Susceptibilities of Candida spp from a South Indian Tertiary Care Hospital
}

\author{
Rajgopal S. $\mathbf{K}^{1}$ \\ ${ }^{1}$ Dr Swapna Kurup Rajgopal, Associate Professor, Department of Microbiology, Karpagam faculty of Medical Sciences \\ and Research, Coimbatore, Tamil Nadu, India.
}

Address for Correspondence: Dr Swapna Kurup Rajgopal. email: eskurup@gmail.com

\begin{abstract}
Introduction: Candida sp. is increasingly being implicated as the cause of both community acquired and Nosocomial infections. With development of new resistance patterns versus the inherent resistance present in some of the species isolated from critical care areas, the complications resulting from long term antibiotics, surgical and medical interventions and environmental colonization by the Candida sp. is becoming more prevalent. Method: Prevalence of different species and their antifungal susceptibilities grown from various samples received in 20 months were studied using semi-automated MiniAPI kits. Results of tests done on 356 isolates were collated and analysed retrospectively. Results: Of the 356 samples, C. tropicalis showed prevalence of $37.07 \%$ as compared to C.albicans $31.1 \%$, C guilliermondii (11.8) and C parapsilosis (6.74\%). Candida sp were found to sensitive to 5-Flucytocine and Amphotericin B. Resistance to Itraconazole was noted more than to Fluconazole. Conclusions: Infections with Candida spp are usually of low virulence and are associated with a few well-defined risk factors as immunocompromised state, Malignancy and steroid therapy. Understanding these risk factors, identifying the species with changing trends in antifungal resistance, instituting infection control practices to reduce morbidity and mortality in critical care areas can improve outcomes.
\end{abstract}

Keywords: Antifungal susceptibilities, Azole resistance Candida species, Species distribution,

\section{Background}

Opportunistic infections by Candida sp are becoming quite common in hospitals today with antifungal resistance, an increasing problem in many wards. With interventions and management of diseases becoming more invasive and complicated, patients' immunity can be affected due to various reasons. Apart from immunosuppression and immunodeficiencies from underlying causes such as chemotherapy, corticosteroids, surgery, malignancy, any manipulation, intervention or prolonged hospital stay increases the risk of infections due to Candida sp. and other fungal pathogens $[1,2]$.

Candida is the commonest fungal pathogen and also can be a contaminant in our laboratories. It causes both invasive and mucosal infections especially in women and in patients with immunity disorders/immunity-

Manuscript received: $14^{\text {th }}$ January 2017

Reviewed: $20^{\text {th }}$ January 2017

Author Corrected: $27^{\text {th }}$ January 2017

Accepted for Publication: $4^{\text {th }}$ February 2017 challenged patients. They have been isolated from a wide variety of samples especially blood sputum pus and urine. Candida species rarely cause infection in physiologically healthy individuals however, a host of factors can lead to Candida infections involving the superficial skin (cutaneous), mucosa (oral oesophageal or vaginal) or organ/ blood stream (systemic or invasive infections).

In Hospital acquired infection Candidiasis is the one of the leading causes with mortality noted between 15 $35 \%$ [3]. Due to the growing size of the population at special risk (neutropenia, immunosuppression, metabolic dysfunction), Candida $\mathrm{sp}$ continues to be threat in the critical care patients with increasing number of Non-albicans Candida (NAC) being isolated.

In a study NAC species which accounted for 10\%-40\% of invasive candidiasis between 1970 to 1990 has now increased to $35 \%-65 \%$ in the recent years $[4,2]$. 
A majority of infections are commonly attributed to five species-C. albicans, C. glabrata, C. parapsilosis, $C$. tropicalis, and $C$. krusei, the species varying from region to region in its predominance. Speciating the Candida isolates is very critical in the management of these diseases as different species vary in their susceptibilities to the antifungal antibiotics tested in vitro [5]. A high level of resistance toward azoles is well known for C. krusei, and few other species while C. parapsilosis and C. guilliermondii are noted for their decreased susceptibility to echinocandins $[5,6]$.

C. guilliermondii and C. lusitaniae are slowly emerging as new causative agents of invasive candidiasis, while C. kefyr, C. dubliniensis, and C. sake, are occasionally associated in few patients in the recent years [7]. Interestingly, significant geographic variation in the frequency of NAC species occurs. While C glabrata and C. parapsilosis were being reported from North America and Europe, recent reports have established them as emerging pathogens in the critical care patients from India too [7]. This compounded with the fact that a few of these fungal pathogens are already inherently resistant or developing resistance further highlights the need for studies in the epidemiological shifts or trends in fungal infections [8-10].

Candida spp. has been associated with poor outcome in $50-60 \%$ of cases of invasive diseases [11-12]. Despite the increasing developments in the field of antifungal agents, the fungal infections especially the yeast pathogens continue to cause increased morbidity and mortality in the affected populations. With the rising trend in organ transplantations and increasing presentations of malignancy and use of potent immunosuppressive drugs, the vulnerable patient population keeps expanding [10, 13, 14].

For early management and better outcomes, identifying the yeast species is essential for monitoring hospital infection rates [15]. Candida spp is one of the most common isolates from both community acquired and nosocomial infection and with the increasing resistance to standard therapeutic agents [16] and evidence of cross resistance [17], standardized methodology and reliable and more rapid reporting becomes essential.

\section{Materials and Methods}

A total of 356 clinically significant Candida isolates were obtained from various samples of patients attending Lakeshore hospital, Kochi, a tertiary care hospital in South India. After ethical clearance from the hospital committee, a retrospective analysis was performed to review records of all patients with positive cultures for candida during the period and to assess the prevalence of in-vitro resistance amongst the isolates. All samples from which Candida spp was isolated as sole or in co-infection with other organisms were included in our study.

Patients with other fungal infections or of age below 18 years were excluded. Age, sex, date of hospital admission/ surgery /intervention, antibacterial or antifungal treatment history presence of indwelling catheter and underlying conditions were noted. Other risk factors for candidiasis were considered, such as presence of any other co-infection or history of Diabetes mellitus, neoplasias, presence of CVC catheter, recent surgery, or immunosuppression (chemotherapy, HIV infection, and steroidal therapy) were noted.

Method- Various samples were collected and treated according to standard microbiological methods. All fungal isolates were processed by routine methods i.e germ tube tests for identification of Candida Albicans, morphological growth patterns on the corn meal/Tween 80 agar, growth at $35^{\circ} \mathrm{C}$ and $43^{\circ} \mathrm{C}$ and speciation was done by MiniAPI ID 32C (BioMérieux Diagnostics, Lyon, France). Susceptibility testing was conducted using MiniAPI ATB Fungus 2 kit (BioMérieux Diagnostics, Lyon, France) according to the manufacturer's instructions complying with CLSI guidelines [18] Data was analysed using MS excel 2010 version.

\section{Results}

Between July 2008 and February 2011, 388 yeast isolates from various samples were collected and submitted for identification and antifungal sensitivity testing in our lab. After clinical correlation, 32 were identified as contaminants and discarded. Of the 388 isolates, 356 were further processed for susceptibility testing. Amongst the yeast isolates, C.tropicalis $132(37.07 \%)$ was the most prevalent followed by C albicans 111(31.1\%) and C. guilliermondii $42(11.8 \%)$. Other isolates as C. krusei , C. kefyr and C sake were found in much lower frequency. Table 1 shows the distribution of the isolates. 
Table-1: Distribution of Candida spp according to samples and clinical conditions.

\begin{tabular}{|c|c|c|c|c|c|c|c|c|}
\hline Candida & Blood & Urine & Sputum & Pus & Fluids & Others & $\begin{array}{l}\text { Underlying } \\
\text { conditions }\end{array}$ & Co-infections \\
\hline $\mathrm{C}$ albicans & 7 & 53 & 25 & 16 & 8 & 2 & $\begin{array}{l}\text { DM, Renal failure } \\
\text { COPD Procedures } \\
\text { Hepatitis urosepsis }\end{array}$ & $\begin{array}{c}\text { CONS MRSA } \\
\text { Gram negative } \\
\text { bacteria }\end{array}$ \\
\hline $\mathrm{C}$ tropicalis & 17 & 65 & 22 & 18 & 8 & 2 & $\begin{array}{c}\text { Cirrhosis DM } \\
\text { urosepsis } \\
\text { neutropenia, } 2^{\text {nd }} \text { line } \\
\text { antibiotics }\end{array}$ & $\begin{array}{c}\text { Gram negative } \\
\text { bacteria, CONS, } \\
\text { Enterococci }\end{array}$ \\
\hline $\begin{array}{c}\mathrm{C} \\
\text { guilliermondii }\end{array}$ & 10 & 19 & 5 & & & 8 & $\begin{array}{c}\text { TCP, malignancy } \\
\text { neutropenia, dialysis }\end{array}$ & Aspergillus sp \\
\hline C.dubliniensis & 5 & & & 2 & 3 & & $\begin{array}{c}\text { Neutropenia, SLE } \\
\text { malignancy } \\
\text { transplant }\end{array}$ & \\
\hline C parapsilosis & 16 & 2 & & & 6 & & $\begin{array}{c}\text { CVC catheter, CAD } \\
\text { neutropenia, long } \\
\text { stay }\end{array}$ & \\
\hline C glabrata & 2 & 4 & 7 & & & & $\begin{array}{c}\text { Neutropenia } \\
\text { Catheter }\end{array}$ & \\
\hline C.krusei & 0 & 4 & & & & 2 & HIV, transplant & \\
\hline C.kefyr & 1 & & & 2 & & & NHL & \\
\hline C.sake & 2 & & & & & & ALL, Transplant & \\
\hline Tricho.asahii & 2 & & & & & & DM nephropathy & Pseudomonas \\
\hline Total (356) & 60 & 144 & 59 & 38 & 25 & & & \\
\hline \multicolumn{9}{|c|}{ S: susceptible; SDD: dose-dependent susceptible; DM: Diabetes mellitus; NHL: Non-Hodgkins Leukemia; ALL: } \\
\hline
\end{tabular}

Table-2: Distribution and Antifungal susceptibilities of the Candida isolates.

\begin{tabular}{|c|c|c|c|c|c|c|c|}
\hline Candida & $\begin{array}{c}\text { Total } \\
\text { isolates }\end{array}$ & $\begin{array}{c}\text { Flucyto- } \\
\text { sine \% }\end{array}$ & $\begin{array}{c}\text { Amphoter- } \\
\text { icin B \% }\end{array}$ & $\begin{array}{c}\text { Fluconazole } \\
\%\end{array}$ & $\begin{array}{c}\text { Itraconazole } \\
\%\end{array}$ & $\begin{array}{c}\text { Voricon- } \\
\text { azole \% }\end{array}$ & $\begin{array}{c}\text { Antifungal } \\
\text { therapy (No. of } \\
\text { isolates) }\end{array}$ \\
\hline C albicans & 111 & 100 & 100 & $\begin{array}{c}86.48+3 \text { S- } \\
\text { DD }\end{array}$ & 81.83 S-DD & 97.29 & 70 \\
\hline C tropicalis & 132 & 100 & 98.11 & 96.22 & 92.45 & 98.48 & 79 \\
\hline C & 42 & 90.47 & 90.47 & $\begin{array}{c}76.192- \\
\text { SDD } \\
\text { guilliermondii }\end{array}$ & $\begin{array}{c}49.882 \text { S- } \\
\text { DD }\end{array}$ & 97.6 & 33 \\
\hline C.dubliniensis & 10 & 100 & 100 & 78.57 & 64.28 & 100 & 8 \\
\hline C parapsilosis & 24 & 100 & 100 & 95.8 & 83.3 & 100 & 15 \\
\hline C glabrata & 13 & 100 & 80 & 601 S-DD & 201 S-DD & 100 & 2 \\
\hline C.krusei & 6 & 100 & 100 & - & 50 & 100 & \\
\hline C.kefyr & 3 & 100 & 100 & 50 & 100 & 100 & \\
\hline C.sake & 2 & 100 & 100 & 100 & 100 & 100 & \\
\hline Tricho.asahii & 2 & 100 & 100 & 100 & 100 & 100 & \\
\hline
\end{tabular}


9.8\% patients had underlying diabetes mellitus, $5 \%$ with transplant history and $8.4 \%$ with cirrhosis. $43.1 \%$ of the patients with candidaemia had a central venous catheter in place while, 95/144(65.9\%) patients had urinary catheter. 207/356 $(58.14 \%)$ patients received antifungal therapy within 1 week of collecting sample. All patients had history of antibacterial treatment. Cephalosporins, Piperacillin Tazobactum, Amoxicillin-clavulanic acid and Carbapenem were commonly prescribed agents.

The results of the susceptibility testing for the isolates are presented in the Table 2. Overall fluconazole exhibited better activity against most species as compared to Itraconazole. All the species had very good sensitivity to Flucytosine Amphotericin B and Voriconazole. Fluconazole results were valid for ketoconazole and miconazole. Sensitive or Intermediate results for some of the species with Fluconazole were also predictive as a susceptible result with Ravuconazole. For Fluconazole, Itraconazole and Voriconazole, the Intermediate category corresponded to S-DD (Susceptible-dose dependent) Category of CLSI which is Susceptible if dose administered is increased. The category includes isolates with MICs that approach usually attainable blood and tissue levels and for which response rates may be lower than for susceptible isolates) [18].

For all Candida sp. isolates, MICs of Voriconazole were $<0.5 \mu \mathrm{g} / \mathrm{ml}$, except in $3 \mathrm{C}$. albicans isolates for which the MIC $>$ $4 \mu \mathrm{g} / \mathrm{ml}$ and four C. guilliermondii and $2 \mathrm{C}$ tropicalis isolates for which the MIC was $>8 \mu \mathrm{g} / \mathrm{ml}$.

Highest resistance to antifungal agents was seen in C.glabrata followed by C.guilliermondii and C tropicalis. Relative low resistance to fluconazole and Itraconazole were also observed in C.dubliniensis, C.albicans and C parapsilosis. C. krusei was found to be resistant to fluconazole.

\section{Discussion}

Candida sp is one of the most common fungal pathogens isolated from various samples collected from patients with immunological dysfunctions and also forms one of the identifying criteria as marker of this dysfunction in patients with AIDS and immunosuppression.

Candida species are environmental contaminants and also present as endogenous flora in most patients. Often in major complications with multifactorial and polymicrobial attributes, it becomes imperative to include antifungal agent coverage especially in patients presenting with neutropenia. Shift in the causal pattern from C.albicans to Non-albicans Candida and increasing reports of resistant species emphasizes the need for a standardized reliable and easy to interpret methodology based on CLSI guidelines which also provides rapid results. The isolation rate from blood culture was low as compared to other studies. Many factors are known to decrease the growth rates in blood culture. Therefore in case of high suspicion of fungal focus elsewhere and worsening clinical parameters, negative blood culture should not preclude fungemia [19]. In urine samples, C. tropicalis was the most common yeast isolated (45.1\%) followed by C. albicans $38.6 \%$ and $\mathrm{C}$, guilliermondii (13.1\%). and $\mathrm{C}$. parapsilosis. This finding was in agreement with many other reports [19-20].
Non-albicans Candida causes 67 to $90 \%$ of nosocomial Candidaemia [21, 22]. Non-albicans Candida were responsible for $87.93 \%$ of candidaemia in our study. There are many risk factors reported for Candidaemia. Isolation of candida from non-sterile sites/samples such as urine and wound swabs can significantly improve outcomes in critical care patients if measures are instituted to control its spread or complications [11, 23].

A total of 21 candida isolates were identified from Ventilator associated pneumonia cases, with coinfection in 3 cases of multi-drug resistant Klebsiella, 1 case of Pseudomonas aeruginosa and 1 case of Staphylococcus aureus. The species recovered were C.albicans 11, C. tropicalis 5 C.glabrata 3 and C.krusei in one case. This correlates well with other study findings [24].

While Candidemia due to C.tropicalis and C.albicans have been reported in many studies, C.guilliermondii has also been gaining importance as causative agent in urosepsis especially in hospitalised patients on urinary catheters diagnosed with malignancy. The incidence of Candidaemia due to $C$. guilliermondii in many studies ranged from $1 \%-3 \%$, based on the geographic region [25]. C. guilliermondii has been known to be associated with malignancy, abdominal procedures and neutropenia. This was in agreement with our findings in 
most patients presenting with fungemia due to this species. C. guilliermondii has been known to be relatively more resistant to antifungal agents than other species which has been as associated with administration of antifungal drugs [25] 8 of the patients who grew C.guilliermondii from two different sites were treated with Caspofungin.Two of these patients died of other complicating causes (AIDS, Chronic Liver disease).

While all strains of C.albicans were susceptible to Amphotericin B and Flucytosine, 16 of the isolated species were resistant to both Fluconazole and Itraconazole, of which 3 isolates were resistant also to Voriconazole. Resistance in C. albicans to Azoles has been noted in many reports [8, 26 27].

$27.5 \%$ of isolates from patients with candidaemia grew C. parapsilosis. All the isolates showed good sensitivity to Flucytosine, Amphotericin B and Voriconazole. CVC tips showed low isolation rate of $\mathrm{C}$. parapsilosis as compared to blood collected from the central and peripheral lines when collected simultaneously.

This agreed favourably with findings from other studies. The method of transporting and processing the tips were associated with either low growth rate or with growth of contaminants $[8,28]$.

Many studies regarding sensitivity of C.glabrata and C.krusei to Fluconazole have emphasized the inherent resistance as in case of C.krusei or varying sensitivity with respect to C.glabrata. In these patients, either Amphotericin B or an echinocandin must be advised [7, 29]. C.glabrata showed higher resistance to Itraconazole as compared to fluconazole and Amphotericin B, consistent with other studies [8 28].

In $13 / 356$ fatal cases, the death was related in part to the complications of the underlying condition as malignancy, surgery, chemotherapy or interventions in post-transplant cases and in part due to ventilator acquired pneumonia [1] due to C.krusei and 2 due to C.tropicalis.

In one patient, fungaemia in a ventilator assisted patient was complicated by Multi-drug resistant Acinetobacter baumanii not responding to treatment. Drug resistances being low comparatively with respect to other studies, the mortality rates were found to be low in our study [11-12].

\section{Conclusion}

Surveillance of the rates of Candida infection in critical areas, reporting of outbreaks and continuous monitoring of antifungal susceptibility patterns will help in choosing the best therapeutic management of complicated cases. Comparison of trends in infection rates amongst hospitals between various Indian cities and their resistance patterns can reveal vital information regarding the breakdown of infection control measures. Most candida infections are of low virulence and only become significant in the vulnerable critical care areas. With the rise in prevalence of inherently azole resistant species and rising use of echinocandins in ICUs, identifying risk factors and controlling the infection early can improve the patient outcome.

\section{Funding: Nil, Conflict of interest: None. Permission of IRB: Yes}

\section{References}

1. Fishman JA, Rubin RH. Infection in organ-transplant recipients. N Engl J Med.1998 Jun 11;338(24):1741-51.

2. Nucci M, Marr KA. Emerging fungal diseases. Clin Infect Dis. 2005 Aug 15;41(4):521-6. Epub 2005 Jul 11.

3. Pfaller MA, Diekema DJ. Epidemiology of invasive candidiasis: a persistent public health problem. Clin Microbiol Rev. 2007 Jan;20(1):133-63.

4. Krcmery V, Barnes AJ. Non-albicans Candida spp. causing fungaemia: pathogenicity and antifungal resistance. J Hosp Infect. 2002 Apr;50(4):243-60.

5. Papon N, Courdavault V, Clastre M, Bennett RJ. Emerging and emerged pathogenic Candida species: beyond the Candida albicans paradigm. PLoS Pathog. 2013; 9 (9): e1003550. doi: 10. 1371/journal. ppat. 1003550. Epub 2013 Sep 26.

6. Walker LA, Gow NA, Munro CA.Elevated chitin content reduces the susceptibility of Candida species to caspofungin. Antimicrob Agents Chemother. 2013 Jan; 57 (1):146-54. doi: 10.1128/AAC.01486-12.

7. Pfaller MA, Diekema DJ, Gibbs DL, Newell VA, Ellis D, et al. Results from the ARTEMIS DISK Global Antifungal Surveillance Study, 1997 to 2007: a 10.5year analysis of susceptibilities of Candida Species to 
fluconazole and voriconazole as determined by CLSI standardized disk diffusion. J Clin Microbiol. 2010 Apr; 48(4):1366-77. doi: 10.1128/JCM.02117-09.

8. Pfaller MA, Moet GJ, Messer SA, Jones RN, Castanheira M. Candida bloodstream infections: comparison of species distributions and antifungal resistance patterns in community-onset and nosocomial isolates in the SENTRY Antimicrobial Surveillance Program, 2008-2009. Antimicrob Agents Chemother. 2011 Feb;55(2):561-6. doi: 10.1128/AAC.01079-10. Epub 2010 Nov 29.

9. Low CY, Rotstein C. Emerging fungal infections in immunocompromised patients. F1000 Med Rep. 2011; 3:14. doi: 10.3410/M3-14. Epub 2011 Jul 1.

10. Pfaller MA, Diekema DJ. Rare and emerging opportunistic fungal pathogens: concern for resistance beyond Candida albicans and Aspergillus fumigatus. J Clin Microbiol. 2004 Oct; 42 (10):4419-31. doi: 10. 1128/JCM.42.10.4419-4431.2004

11. Karabinis A, Hill C, Leclercq B, Tancrède C, Baume D, Andremont A. Risk factors for candidemia in cancer patients: a case-control study. J Clin Microbiol. 1988 Mar;26(3):429-32.

12. Bross J, Talbot GH, Maislin G, Hurwitz S, Strom BL. Risk factors for nosocomial candidemia: a casecontrol study in adults without leukemia. Am J Med. 1989 Dec;87(6):614-20.

13. Chitasombat MN, Kofteridis DP, Jiang Y, Tarrand J, Lewis RE, Kontoyiannis DP. Rare opportunistic (non-Candida, non-Cryptococcus) yeast bloodstream infections in patients with cancer. J Infect. 2012 Jan; 64 (1):68-75. doi: 10.1016/j.jinf.2011.11.002. Epub 2011 Nov 11.

14. Walsh TJ, Groll A, Hiemenz J, Fleming R, Roilides E, Anaissie E. Infections due to emerging and uncommon medically important fungal pathogens. Clin Microbiol Infect. 2004 Mar;10 Suppl 1:48-66.

15. Bassetti M., Taramasso L., Nicco E., Molinari M.P., Mussap M., Viscoli C. Epidemiology, species distribution, antifungal susceptibility and outcome of nosocomial candidemia in a tertiary care hospital in Italy. PLoS One. 2011;6(9): e24198. doi: 10.1371/ journal. pone. 0024198 .
16. Spellberg BJ, Filler SG, Edwards JE Jr. Current treatment strategies for disseminated candidiasis. Clin Infect Dis. 2006 Jan 15;42(2):244-51. Epub 2005 Dec 2.

17. Magill SS, Shields C, Sears CL, Choti M, Merz WG. Triazole cross-resistance among Candida spp.: case report, occurrence among bloodstream isolates, and implications for antifungal therapy. J Clin Microbiol. 2006 Feb;44(2):529-35. doi: 10.1128/JCM. 44.2.529-535.2006

18. CLSI. 2008. Reference method for broth dilution antifungal susceptibility testing of yeasts, 3rd ed. M27A3. Clinical and Laboratory Standards Institute, Wayne, PA.

19. Melvin P. Weinstein, Michael L. Towns, Seth M. Quartey, Stanley Mirrett, Larry G. Reimer, Giovanni Parmigiani, L. Barth Reller; The Clinical Significance of Positive Blood Cultures in the 1990s: A Prospective Comprehensive Evaluation of the Microbiology, Epidemiology, and Outcome of Bacteremia and Fungemia in Adults. Clin Infect Dis 1997; 24 (4): $584-$ 602. doi: $10.1093 /$ clind/24.4.584

20. Chien-Yuan Chen1,2, Shang-Yi Huang1, Jih-Luh Tang1.Clinical features of patients with infections caused byCandida guilliermondii and Candida fermentati and antifungal susceptibility of the isolates at a medical centre in Taiwan, 2001-10. J Antimicrob Chemother. 2013 Nov;68(11):2632-5. doi: 10.1093/ jac/dkt214.

21. Verma AK, Prasad KN, Singh M, Dixit AK, Ayyagari A. Candidaemia in patients of a tertiary health care hospital from north India. Indian J Med Res. 2003 Mar;117:122-8.

22. Chakrabarti A, Mohan B, Shrivastava SK, Marak RS, Ghosh A, Ray P. Change in distribution and antifungal susceptibility of Candida species isolated from candidaemia cases in a tertiary care centre during 1996-2000. Indian J Med Res. 2002 Jul; 116:5-12.

23. Hajjeh RA, Sofair AN, Harrison LH, Lyon GM, Arthington-Skaggs BA, Mirza SA, Phelan M, Morgan J, Lee-Yang W, Ciblak MA, Benjamin LE, Sanza LT, Huie S, Yeo SF, Brandt ME, Warnock DW. Incidence of bloodstream infections due to Candida species and in vitro susceptibilities of isolates collected from 1998 to 
2000 in a population-based active surveillance program. J Clin Microbiol. 2004 Apr;42(4):1519-27.

24. Koenig SM, Truwit JD. Ventilator-associated pneumonia: diagnosis, treatment, and prevention. Clin Microbiol Rev. 2006 Oct;19(4):637-57.

25. Pfaller MA, Diekema DJ, Mendez M, et al. . Candida guilliermondii, an opportunistic fungal pathogen with decreased susceptibility to fluconazole: geographic and temporal trends from the ARTEMIS DISK antifungal surveillance program, J Clin Microbiol. 2006 Oct;44(10):3551-6. DOI: 10.1128/ JCM. 00865-06

26. Vimal S. Rathod, Jayant S. Raut, S. Mohan Karuppayil. In Vitro Antifungal Susceptibility reveals occurrence of Azole Resistance among clinical isolates of Candida albicans. Asian J Pharm Clin Res, Vol 5,
Issue 3, 2012, 170-173. http://www.ajpcr.com/ Vol5 Issue 3/1100.pdf

27. Kothari A, Sagar V. Epidemiology of candida bloodstream infections in a tertiary care institute in India. Indian J Med Microbiol. 2009 Apr-Jun;27 (2): 171-2. doi: 10.4103/0255-0857.49440.

28. Takakura S, Fujihara N, Saito T, Kudo T, Iinuma Y, Ichiyama $S$. National surveillance of species distribution in blood isolates of Candida species in Japan and their susceptibility to six antifungal agents including voriconazole and micafungin. J Antimicrob Chemother. 2004 Feb;53(2):283-9. Epub 2003 Dec 19.

29. Kanafani ZA, Perfect JR. Antimicrobial resistance: resistance to antifungal agents: mechanisms and clinical impact. Clin Infect Dis. 2008 Jan 1;46(1):120-8. doi: $10.1086 / 524071$.

\section{How to cite this article?}

Rajgopal S. K. Prevalence and Antifungal Susceptibilities of Candida spp from a South Indian Tertiary Care Hospital. Int J Med Res Rev 2017;5(02):98-104. doi:10.17511/ijmrr. 2017.i02.01. 